\title{
Geociências
}

\section{Caracterização de eletrofácies por meio de ferramentas estatísticas multivariadas}

\author{
(Electrofacies characterization using multivariate \\ statistical tools)
}

Henrique Rosa

Petrobras S/A. E-mail: henros@petrobras.com.br

Saul B. Suslick

Departamento de Geologia e Recursos Naturais - IG/UNICAMP Centro de Estudos de Petróleo - Cepetro/UNICAMP. E-mail: suslick@ige.unicamp.br

Alexandre C. Vidal

Departamento de Geologia e Recursos Naturais - IG/UNICAMP Centro de Estudos de Petróleo - Cepetro/UNICAMP. E-mail: vidal@ige.unicamp.br

Gláucia K. Sakai

Departamento de Geologia e Recursos Naturais - IG/UNICAMP. E-mail: glaucia.sakai@gmail.com

\begin{abstract}
Resumo
Nesse artigo é apresentado um método de caracterização de eletrofácies com base em análises estatísticas multivariadas, o qual utiliza dados de perfis geofísicos de poços referentes às classes litológicas identificadas nos testemunhos desses poços. Como exemplo de aplicação, utiliza-se um conjunto de dados, o qual inclui perfis e descrições de testemunhos de poços verticais do Campo de Namorado, localizado na bacia de Campos. Os resultados obtidos mostram um bom desempenho das técnicas em diversos procedimentos automatizados para a caracterização de eletrofácies. Além disso, essas técnicas permitem que se obtenham avaliações referentes à qualidade da amostragem, no que se refere aos ajustes das mesmas com as profundidades de perfis, além de proporcionar agilidade ao processo de investigação exploratória de dados de perfis em relação às classes litológicas a estes associadas.
\end{abstract}

Palavras-chave: Eletrofácies, análise estatística multivariada, exploração de Petróleo.

\begin{abstract}
This paper presents a method for electrofacies characterization which is based upon multivariate statistics analysis applied to well log data obtained from lithological classes identified in the core samples of oil and gas wells. As a case study it is used a data set which includes well logs, macroscopic reports, and sets of core samples extracted from vertical wells, located in the oil-producing field of Namorado in the Campos Basin, Brazil. The results show a good performance of the proposed approach for electrofacies characterization. Furthermore, all the statistical tests applied in this study allow the researcher to obtain information about the quality of the sampling process and the accuracy related to the correlation between the sampling and the logging depth, speeding-up the process of the exploratory investigation by using well log data associated to the lithological classes present in the cored intervals from oil well.
\end{abstract}

Keywords: Electrofacies, Multivariate Statistical Analysis, Petroleum Exploration. 


\section{Introdução}

Os estudos relacionados à caracterização de eletrofácies por meio de perfis geofísicos de poços e de dados geológicos diretos - amostras de testemunhos e amostras de calha - têm sido amplamente discutidos devido à importância e a grande aplicabilidade nas rotinas que envolvem a modelagem geológica de reservatórios petrolíferos (Serra, 1986a,b; Doveton, 1994; Rider, 2000). Os métodos tradicionais de caracterização de eletrofácies incluem a utilização de softwares que permitem a operação com dados de perfis geofísicos de poços, baseados nas propriedades físicas de cada perfil, associados aos dados de testemunho, obtidos do contato direto com a rocha. Além da associação de diferentes tipos de dados para a definição de eletrofácies, outro problema está relacionado à representatividade dos dados, pois os testemunhos são provenientes de alguns intervalos do campo, enquanto que os perfis são corridos ao longo de todos os poços.

Nesse sentido, esse trabalho apresenta um método para que se obtenha a convergência entre o número de classes litológicas identificadas em testemunhos e as eletrofácies indicadas pelos perfis, visando a facilitar a utilização conjunta dessas informações nos diversos procedimentos (softwares) disponíveis no mercado para a caracterização de eletrofácies. Uma das etapas do processo de convergência requer o uso das ferramentas estatísticas, as quais utilizam um conjunto de observações de referência ou treinamento ("training sets"), contendo todas as informações possíveis (por exemplo, perfis dos poços e/ou testemunhos), que permitam criar uma regra classificatória para que as demais observações possam ser inferidas e agrupadas em conjuntos homogêneos.

\section{Metodologia: convergência entre classes litológicas e eletrofácies}

Um dos grandes desafios na análise de informações na etapa de exploração de petróleo refere-se ao valor da informação. Nos processos decisórios, sempre é necessário um significativo volume de informações para que se possa reduzir as incertezas e os riscos envolvidos. De uma maneira geral, as informações se apresentam de forma incompleta (quantidade e qualidade) e nem sempre de forma convergente, devido às características do processo exploratório, que envolve decisões de estratégia, tecnologia e custos associados (Suslick \& Schiozer, 2004). Por isso, é fundamental, na caracterização geológica dos reservatórios, a utilização conjunta de todas as informações disponíveis, como os dados de testemunho, amostras de calha, sísmica e os perfis geofísicos de poços.

Algumas técnicas estatísticas multivariadas permitem realizar essas inferências e convergências sem incorrer em custos adicionais na geração de novas informações (Doveton, 1994). Na literatura, destacam-se contribuições importantes na classificação de fácies obtidas com a utilização de ferra- mentas estatísticas como a análise multivariada de dados, tais como a análise discriminante (Bucheb, 1991; Avseth et al., 2001; Tang et al., 2004, Flexa et al., 2004 e Li e Anderson-Sprecher, 2006). Essa técnica necessita de um conjunto de observações relativamente grande, mas o uso combinado com outras técnicas estatísticas vem permitindo operar com uma dimensão um pouco mais reduzida da amostra de referência, que é uma das contribuições da metodologia proposta nesse trabalho e que foi testada com relativo sucesso por Rosa (2006). Outros tipos de técnicas de classificação de fácies foram obtidos com o uso de redes neurais (Bhatt \& Helle, 2002) e uso de técnicas de lógica nebulosa (Cuddy, 2000), mas que não serão aqui tratados, pois escapam ao escopo desse trabalho.O método proposto nesse trabalho buscou estabelecer convergências entre o número de classes litológicas identificadas em testemunhos e as eletrofácies indicadas pelos perfis. Entretanto vale ressaltar que os passos aqui propostos se resumem ao tratamento dos dados referentes aos intervalos testemunhados dos poços utilizados nesse estudo. A Figura 1 exibe os principais passos da metodologia utilizada no estudo.

Os passos iniciais envolvem a análise seqüencial de testemunhos e dos perfis utilizados, a calibração rocha-perfil e a definição das eletrofácies. Para avaliar o grau de similaridade entre os diferentes agrupamentos de eletrofácies e a classificação adotada nesse trabalho oriunda da Petrobras, utilizouse a análise de agrupamento em dois estágios. Maiores detalhes sobre o algoritmo empregado para avaliar as similaridades pode ser encontrados em Kaufman e Rousseeuw (1990), Johnson e Wichern (1992), Backer (1995), Gordon (1999) e Davis (2002). A principal vantagem desse procedimento é a possibilidade de se manipularem variáveis categóricas (p.ex., litologias), associadas a variáveis contínuas (perfis), por meio de uma distribuição multinomial (vários grupos possíveis) e normais, supondo-se que as variáveis são independentes entre si. Nesse estudo, o objetivo é reagrupar a variável categórica denominada "litologia" em cinco classes de rochas, definidas pela descrição dos testemunhos dos poços. Cada uma das cinco classes de rochas é caracterizada por um conjunto de variáveis contínuas (perfis de Raios Gama, Sônico, de Densidade Total da Formação e de Porosidade Neutrônica), as quais são coletadas frente aos seus intervalos de ocorrência, dentro do intervalo testemunhado e que foram classificadas em rochas reservatórios e não-reservatórios. Detalhes sobre os métodos de perfilagem e a sua utilização na caracterização das eletrofácies por intermédio das medidas dos perfis de Raio Gama (RG), Sônico (Dt), Densidade de Formação $(\rho B)$ e Porosidade Neutrônica $(\varphi \mathrm{N})$ utilizados no presente trabalho podem ser encontrados em Serra (1986a, 1986b), Schlumberger (1987), Rider (2000) e Rosa (2006).

O passo seguinte consiste na verificação da validade das classes de eletrofácies preestabelecidas, através de análise quantitativa (análise estatística exploratória de dados) integrando os dados de perfilagem e informações oriundas dos testemunhos. 
O último passo verifica quais são as amostras mais representativas de cada uma das eletrofácies. Os dados são separados em três conjuntos, sendo o primeiro correspondente a uma amostra de treinamento, a qual será usada na elaboração da regra discriminante; o segundo é utilizado para validação e o terceiro, para predição, do qual não se dispõe de informações de testemunho. A escolha das amostras é fundamental para o sucesso da próxima etapa, pois esses dados, denominados amostras de treinamento, serão utilizados na etapa posterior, na elaboração da função discriminante. As amostras de verificação são observações que serão utilizadas para a validação da função discriminante.

Na regra de classificação com abordagem supervisionada, partiu-se de um número preestabelecido de grupos (as litofácies descritas nos testemunhos), com base nas relações entre esses grupos e os respectivos dados de perfis, tornando possível a geração de funções discriminantes que melhor separem os grupos de litofácies, para que, em seguida, eles possam ser extrapolados para as demais amostras.

A função discriminante linear e quadrática foi aplicada em seis poços com objetivo de comparar a classificação obtida pela função discriminante com os trechos testemunhados [a análise discriminante linear assume homogeneidade da matriz de covariância para as diferentes classes, enquanto a análise discriminante quadrática é utilizada se a matriz de covariância apresentar heterogeneidade (Tabachnick \& Fidell, 2001)]. Nas situações nas quais a validação cruzada aponta para um índice de sucesso aceitável, a função discriminante é aplicada aos trechos não perfilados. Os passos da análise discriminante podem ser resumidos em: (i) criação de uma função discriminante a partir da amostra de treinamento; (ii) cálculo a distância de Mahalanobis e (iii) cálculo da probabilidade condicional a partir da distância de Mahalanobis.

Conforme mostra a Figura 1, foi aplicada uma seqüência de procedimentos e métodos estatísticos combinando a

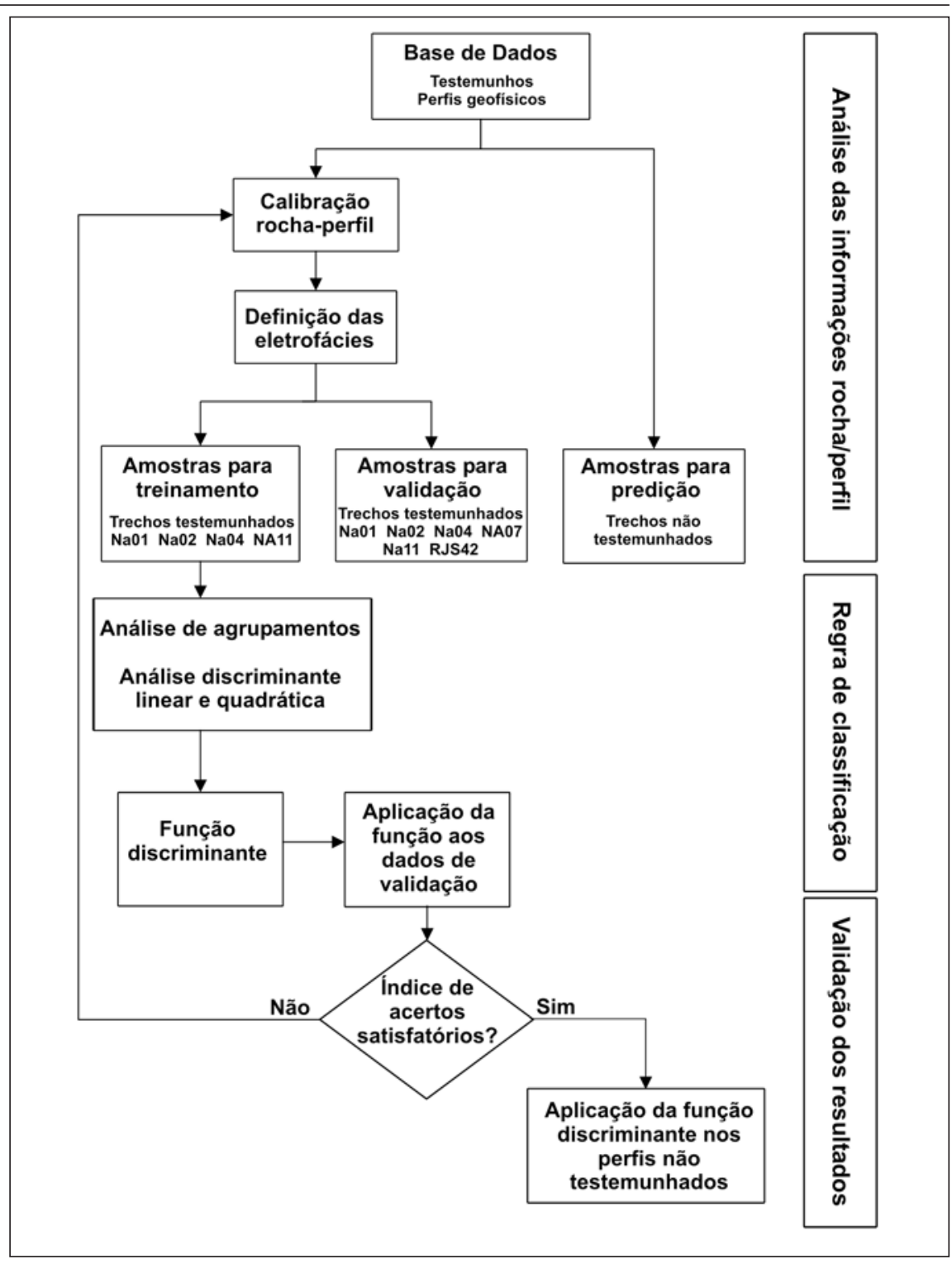

Figura 1 - Fluxograma das etapas da metodologia de caracterização das eletrofácies.

análise de agrupamento em dois estágios e a análise discriminante, utilizando o conjunto de dados de perfis e de testemunhos dos poços NA01, NA02, NA04, NA07, NA11 e RJS42, do Campo Escola de Namorado, localizado na bacia de Campos (Figura 2).

\section{Resultados e discussões}

A partir da análise qualitativa das informações oriundas dos testemunhos, as 20 litofácies originais, definidas pela Petrobras e extraídas do conjunto de dados do Campo Escola de Namorado, cedido pela ANP, foram testadas para diferentes possibilidades de agrupamentos, conforme o fluxograma proposto (Figura 1). De todos os agrupamentos analisados, a configuração final, que apresenta os menores desvios para as rochas descritas em testemunho, corresponde a cinco classes (eletrofácies).

As cinco classes são referentes a: Arenito (A), Arenito Argiloso (AA), Arenito Cimentado (AC), Carbonato (C) e Folhelho (F), conforme mostra a Tabela 1. A Figura 3 apresenta os resultados dos diagramas de dispersão e dos histogramas dos dados de perfilagem. Nessa figura, observa-se haver forte correlação 


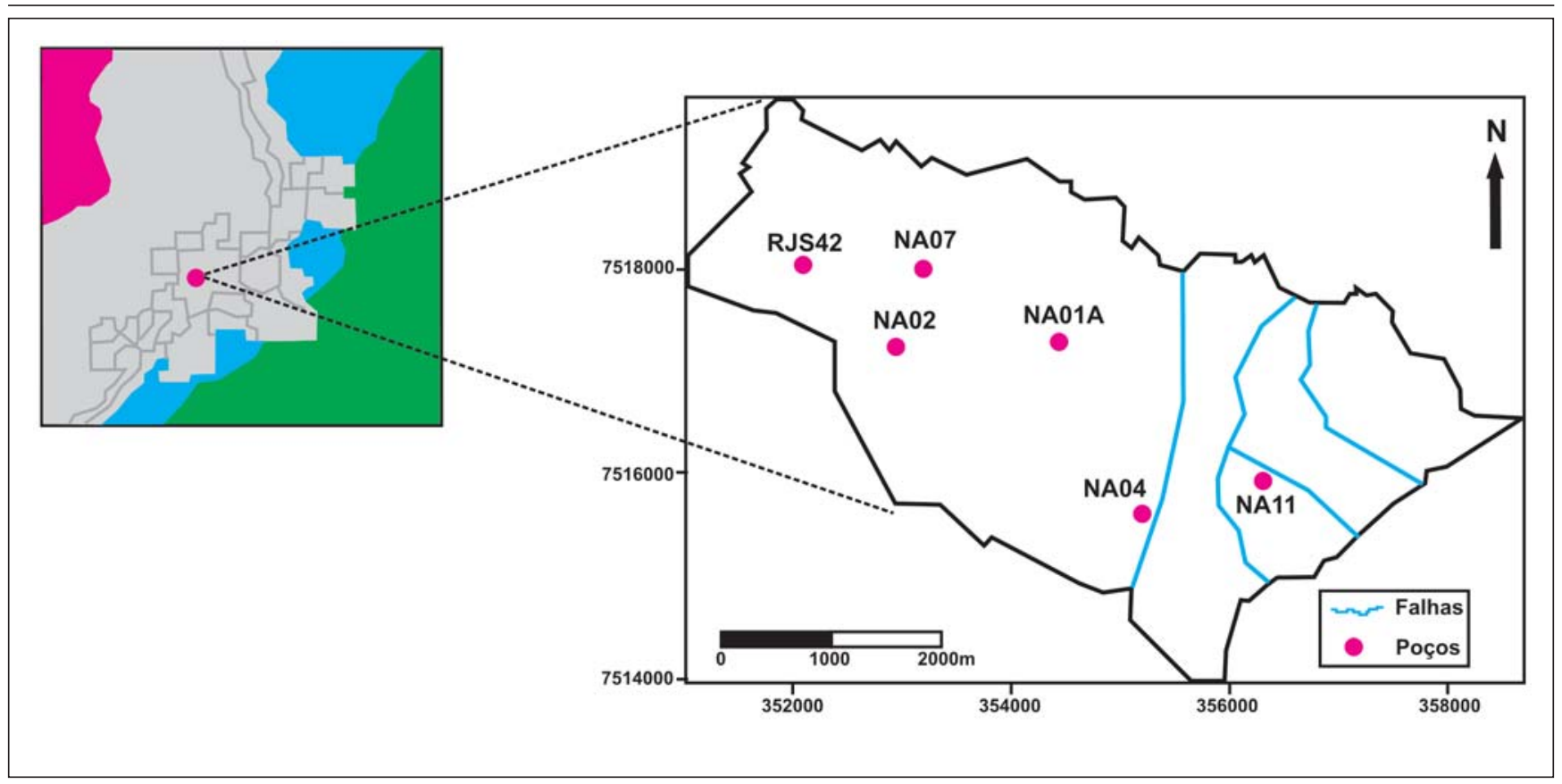

Figura 2 - Mapa de localização do bloco do Campo de Namorado e dos poços selecionados.

entre o cruzamento das variáveis Dt, RG, $\varphi N$ e $\rho B$; Dt e $\varphi N$; Dt e $\rho B$ e $\varphi N$ e $\rho B$. Oberva-se, ainda, que existem pontos fora da curva, os quais podem influenciar negativamente na classificação das eletrofácies. Os diagramas da Figura 3 indicam que, nesse estudo, as variáveis $\rho B$ e RG podem ser utilizadas como bons discriminantes.

O perfil sônico (Dt) indica o tempo que um pulso sonoro leva para atravessar um intervalo de formação (Schlumberger, 1987). O intervalo de trânsito é maior nas rochas menos densas, diferenciando os arenitos cimentados, mais densos, dos arenitos limpos. As medidas de Raios Gama (RG) assumem importância na distinção do grau de argilosidade presente nas rochas. Observa-se que os folhelhos e arenitos argilosos apresentam leitura de Raios Gama superiores a $60^{\circ} \mathrm{API}$. Embora as medidas de RG apresentem maior amplitude para folhelhos, há possibilidade de que os arenitos argilosos e folhelhos sejam confundidos por apresentarem leituras semelhantes.

Ressalta-se que os reservatórios do Campo de Namorado são constituídos por arenitos arcoseanos, o que lhes atribui uma emissão de radioatividade natu-
Tabela 1 - Classificação da Petrobras para as litofácies e eletrofácies adotadas nesse estudo.

\begin{tabular}{|c|c|c|}
\hline \multirow{2}{*}{$\begin{array}{c}\text { Eletrofácies - } \\
\text { Classificação adotada }\end{array}$} & \multicolumn{2}{|r|}{ Classificação da Petrobras } \\
\hline & Litofácies & Denominação \\
\hline Arenito $(A)$ & $\begin{array}{l}4 \\
6 \\
7 \\
8\end{array}$ & $\begin{array}{l}\text { Conglomerados Residuais } \\
\text { Arenito Grosso Amalgamado } \\
\text { Arenito Médio Laminado } \\
\text { Arenito Médio Gradado ou Maciço }\end{array}$ \\
\hline Arenito Argiloso (AA) & $\begin{array}{c}3 \\
10 \\
11 \\
15 \\
22\end{array}$ & $\begin{array}{l}\text { Diam ictito Arenoso Lamoso } \\
\text { Arenito/Folhelho Interestratificado } \\
\text { Arenito/Folhelho, finam ente } \\
\text { estratificado } \\
\text { Interlam inado Arenoso, Bioturbado } \\
\text { Siltito Argiloso/Arenito }\end{array}$ \\
\hline Arenito Cimentado (AC) & $\begin{array}{l}9 \\
21\end{array}$ & $\begin{array}{l}\text { Arenito Médio Cim entado } \\
\text { Arenito Cim entado, com Feições de } \\
\text { Escorregam ento }\end{array}$ \\
\hline Carbonato (C) & $\begin{array}{l}1 \\
2 \\
13 \\
17 \\
18\end{array}$ & $\begin{array}{l}\text { Interlam inado Lamoso Deform ado } \\
\text { Conglomerados e Brechas } \\
\text { Carbonáticas } \\
\text { Interlam inado Siltito Argiloso e Marga } \\
\text { Marga Bioturbada } \\
\text { Ritm ito }\end{array}$ \\
\hline Folhelho (F) & $\begin{array}{l}16 \\
20\end{array}$ & $\begin{array}{l}\text { Siltito Argiloso Estratificado } \\
\text { Folhelho Radioativo } \\
\text { Interlam inado de Siltito e Folhelho } \\
\text { Deformado } \\
\text { Folhelho Síltico, com níveis de Marga } \\
\text { Bioturbada }\end{array}$ \\
\hline
\end{tabular}


ral acima dos padrões normais para os arenitos líticos ou para aqueles constituídos predominantemente por quartzo. Dessa forma, espera-se que, mesmo nos intervalos com pouca argilosidade, as curvas dos perfis de Raios Gama apresentem valores acima do esperado para arenitos limpos.

As medidas de porosidade neutrônica $(\varphi N)$ indicam o índice de hidrogênio das formações, o qual reflete diretamente a porosidade (Rider, 2004). Os grupos Arenito, Arenito Argiloso e Folhelho apresentam uma maior porcentagem de porosidade em relação ao Arenito Cimentado e Carbonato. Em arenitos, assume-se que os átomos de hidrogênio estão associados às moléculas de água ou de hidrocarbonetos. Em rochas contendo argila, a porosidade pode se relacionar à presença de microporosidade. Tratando-se de Arenito Cimentado, a faixa ampla de valores pode indicar a variação de cimento nos poros. O Perfil de Densidade da Formação $(\rho B)$ constitui uma ferramenta útil para a avaliação da porosidade das formações sedimentares (Schlumberger, 1987). Assim, o grupo Arenito apresenta-se bem caracterizado por esse perfil. Entre as medidas geofísicas, a Densidade de Formação é a que melhor discrimina a eletrofácies Carbonato.

Os trechos testemunhados dos poços NA01, NA02, NA04 e NA11 foram utilizados como dados de treinamen- to, pois juntos incluem amostras representativas das cinco eletrofácies estabelecidas confirmadas pelos testes da análise estatística descritiva. Deve-se salientar que as cinco fácies não ocorrem, necessariamente, em todos os seis poços escolhidos. Os testemunhos dos poços NA02 e RJS42 mostram apenas conteúdo litológico de origem siliciclástica, enquanto que os trechos testemunhados do poço NA11 revelam espessos intervalos carbonáticos. A partir dos dados de treinamento e com o auxílio do programa SAS ${ }^{\circledR}$, obteve-se a função discriminante linear e quadrática para os respectivos poços. A validação cruzada, a qual é utilizada para avaliar o desempenho da função discriminante, foi aplica-

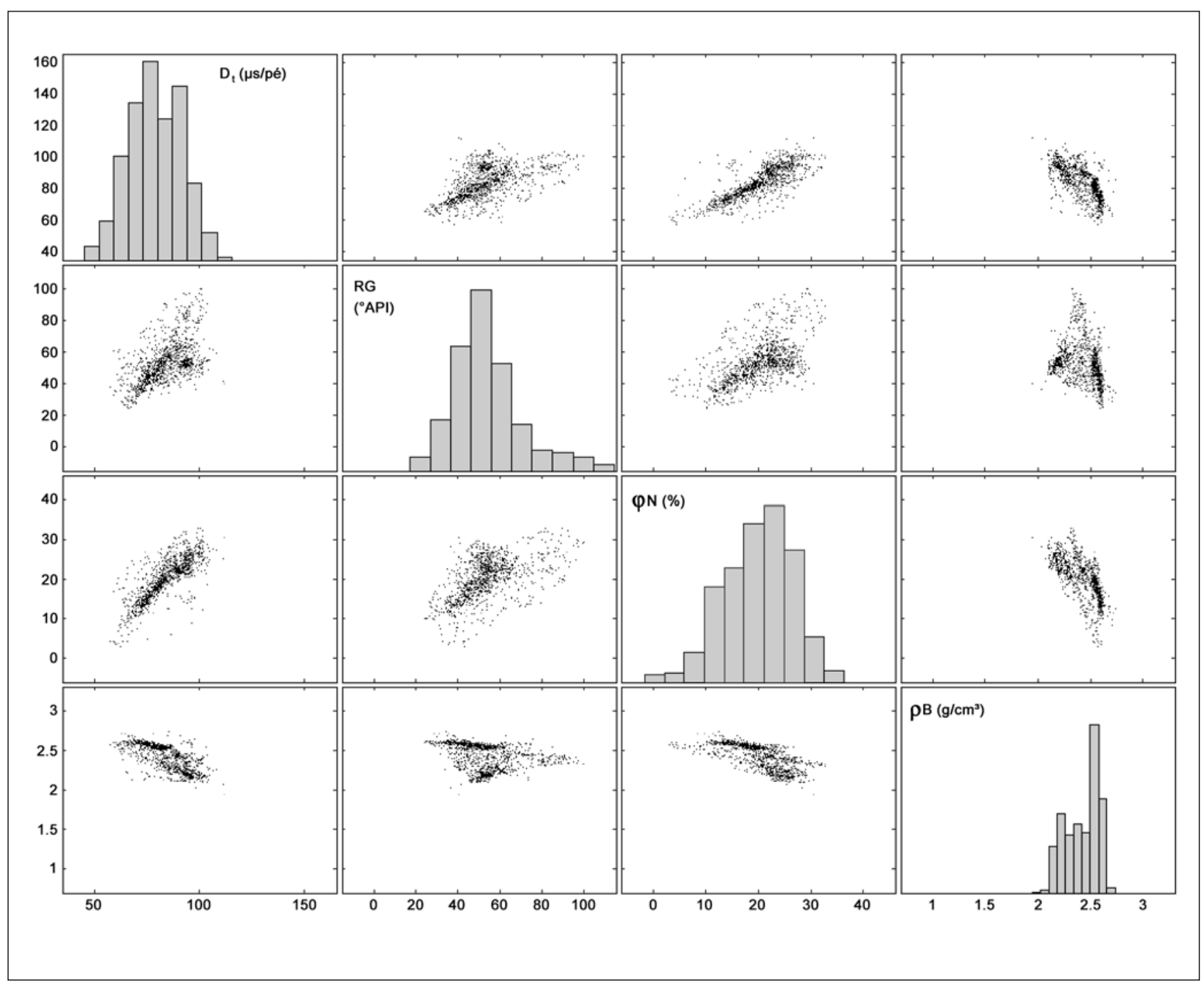

Figura 3 - Matriz com os diagramas de dispersão e histogramas das variáveis geofísicas. 
da nas amostras dos poços NA01, NA02, NA04 e NA11, bem como nos poços NA07 e RJS42. A Figura 4 apresenta os resultados obtidos com a análise discriminante quadrática (ADQ) para o poço NA07, com as probabilidades resultantes (probabilidades condicionais - ADQ Eletrofácies) e as classificações das eletrofácies. Na função discriminante, assume-se que as amostras, associadas às suas variáveis em perfis (Dt, RG, $\varphi \mathrm{N}, \rho \mathrm{B}$ ), são classificadas nos grupos específicos de eletrofácies (Tabela 1), somente com valores de probabilidades acima de $60 \%$. As curvas de probabilidade para cada eletrofácies são mostradas à esquerda da ilustração. A primeira coluna da esquerda para direita indica a classificação obtida, enquanto que, para efeito de comparação, as duas últimas colunas da direita indicam as eletrofácies e as litofácies, respectivamente, observadas nos trechos testemunhados.

A Figura 5 apresenta os resultados da validação cruzada expressa por intermédio dos índices de acertos das classificações obtidas por poço e por eletrofácies, tanto pela análise discriminante linear (ADL), quanto pela quadrática (ADQ). Apesar dos índices finais de acertos se mostrarem próximos, sendo $74 \%$ para a ADL e 78\% para ADQ, observa-se que, no processo de validação, o percentual de acerto para as eletrofácies portadoras de hidrocarbonetos (Arenito, Arenito Argiloso e Arenito Cimentado) foi maior para a ADQ, como demonstra a Figura 5.

No poço NA02, o índice de acerto total chegou a $91 \%$ para a ADQ e foi o melhor resultado obtido. O poço com o pior índice de acerto foi o RJS42, 32\% para ADL. No entanto, deve-se mencionar que a análise de índice de acerto por poço refere-se somente aos percentuais de acerto associados às características das litofácies presentes nos poços. A eletrofácies Arenito é o principal representante das características do reservatório. A validação cruzada mostrou que, para a ADQ, 78\% das amostras deste grupo foram classificadas corretamente e, para ADL, 70\%. Na ADQ, apenas 8 amostras de Folhelho e 6 amostras de Carbonato foram classificadas como Arenito.

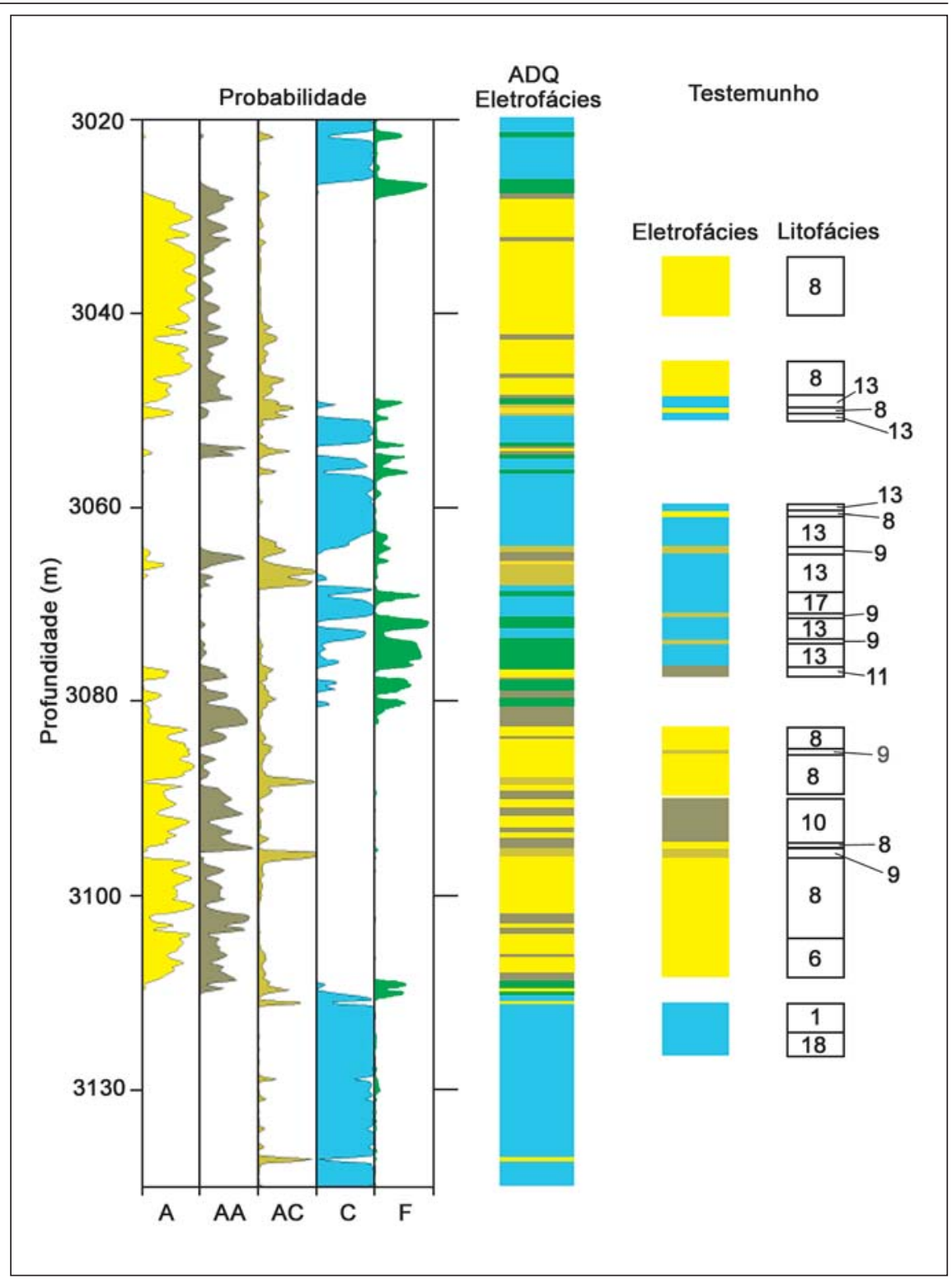

Figura 4 - Classificação das eletrofácies pela análise discriminante quadrática (ADQ Eletrofácies) do poço NA07 para as eletrofácies $(A=$ arenito, $A A=$ Arenito Argiloso, $A C=$ Arenito Cimentado,$C=$ Carbonato e $F=$ Folhelho). $A$ escala vertical representa a profundidade do poço. As cinco primeiras colunas da direita representam as probabilidades para as referidas eletrofácies obtidas de acordo com a regra discriminante. As duas últimas colunas da esquerda indicam a classificação das eletrofácies e litofácies observadas nos trechos testemunhados.

Nos poços NA01 e NA02, o índice de acerto, para Arenito, é de $100 \%$. O resultado, igualmente, foi adequado para o poço NA07, chegando a 95\% de acerto. Já para o poço RJS42, apenas $44 \%$ dos membros da classe Arenito foram classificados corretamente. O pior resultado foi para o poço NA11, onde 8 das 34 amostras foram classificadas como Arenito Cimentado.
Para a eletrofácies Arenito Argiloso, o índice de acerto foi de $68 \%$, para ADQ, e $56 \%$, para ADL. Cerca de $20 \%$ foram classificados incorretamente como Arenito e, aproximadamente, 9\% como Folhelho. As causas das classificações incorretas podem estar relacionadas às variações de argilosidade de uma amostra para a outra, além do fato de essa 


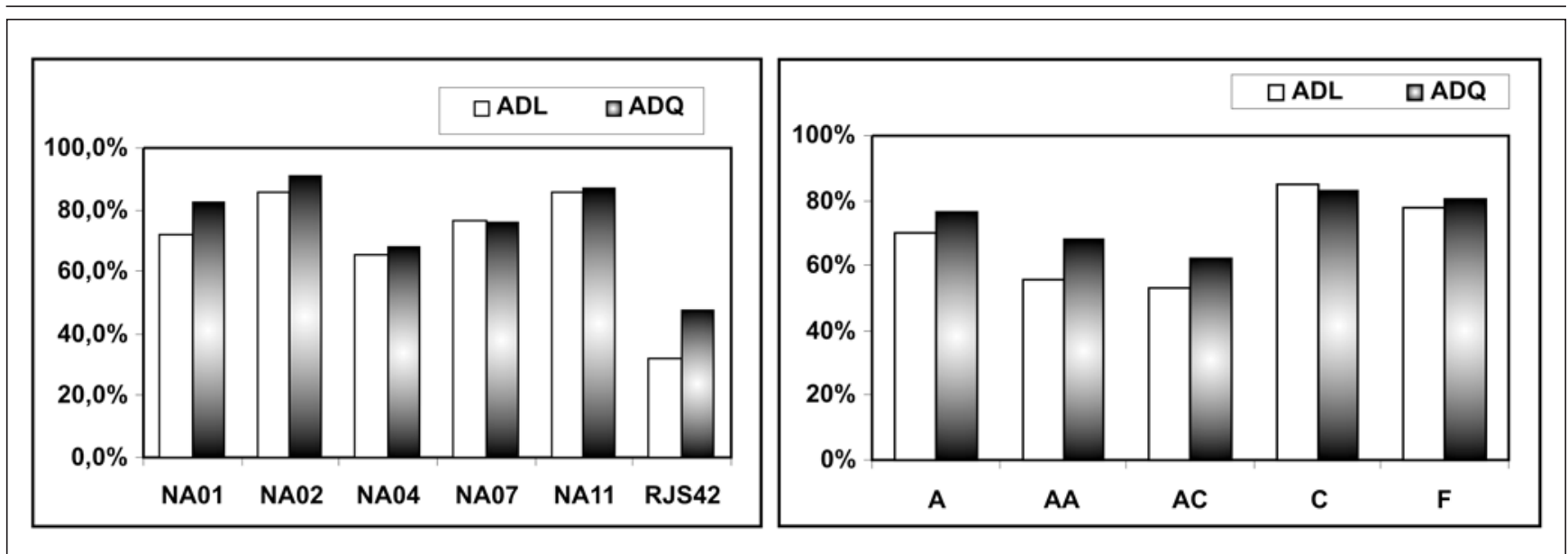

Figura 5 - Índice das classificações positivas por poços e por eletrofácies obtidas. ADL - Análise Discriminante Linear; ADQ - Análise Discriminante Quadrática.

classe abranger litofácies que apresentam intercalações arenito e folhelho, e as medições serem realizadas em intervalos de $20 \mathrm{~cm}$. Para a eletrofácies Arenito Cimentado, o índice de acerto foi o menor, com $62 \%$, para ADQ, e $53 \%$, para ADL. Verificaram-se semelhanças em relação aos perfis geofísicos com a eletrofácies Arenito.

A eletrofácies Carbonato obteve um índice médio de acerto de $84 \%$. A classificação incorreta das amostras ocorreu, provavelmente, devido ao fato de rochas como marga estarem incluídas nessa classe. Observaram-se indícios de hidrocarbonetos em alguns trechos, no entanto o objetivo desse trabalho restringe-se apenas à distinção de reservatórios siliciclásticos. A eletrofácies Folhelho obteve um índice de acerto superior a $78 \%$. Cerca de $12 \%$ das amostras foram classificadas como Arenito Argiloso, possivelmente devido à semelhança das respostas das medições geofísicas.

AAnálise Discriminante Quadrática mostrou-se mais apropriada para o estudo dos poços NA01, NA02, NA04, NA11 e RJS42 do Campo de Namorado, da bacia de Campos. O principal reservatório é o Arenito, enquanto que Arenitos Argilosos e Arenitos Cimentados são reservatórios de baixa qualidade. Portanto a classificação incorreta dessas litologias não proporciona impactos negativos.

\section{Conclusões}

Esse estudo apresenta um método de convergência entre a classificação litológica proveniente da análise seqüencial de testemunhos e as classes litológicas identificadas com base nos perfis geofísicos de poços de petróleo, no sentido de se caracterizarem eletrofácies.

Vale ressaltar o maior valor analítico da análise discriminante, visto que a mesma avalia os agrupamentos por meio da geração de uma função discriminante, com base em combinações lineares entre as observações, e reclassifica tais agrupa- mentos por meio dessa função. Posteriormente, esta verifica se a proporção de casos em que a variável de grupo original é igual ao grupo no qual a observação foi alocada por meio da função discriminante.

Dessa forma, observa-se que, para o poço 3-NA02-RJS, onde existe uma boa correlação entre a profundidade de amostragem e a profundidade dos perfis, além de uma boa caracterização das litologias descritas em testemunho em relação às amostras de perfis, o melhor resultado de caracterização de eletrofácies, em relação à análise discriminante, é aquele oriundo das análises qualitativas convencionais. Essa constatação empírica indica uma boa robusteza da metodologia, pois as observações nesse poço são levantadas com base em conceitos geológicos, em conhecimento sobre a avaliação de formações por meio de perfis, além de uma grande dose de experiência na área de petrografia sedimentar.

Do anteriormente exposto, conclui-se que o método proposto nesse estudo se mostra eficiente para caracterizar eletrofácies por meio da associação de informações litológicas macroscópicas com os atributos petrofísicos obtidos dos perfis de poços, referentes aos intervalos testemunhados dos mesmos. Além disso, o método possibilita a avaliação da qualidade das correlações entre as profundidades das amostragens e as profundidades dos perfis, corelações que são realizadas durante a análise seqüencial dos testemunhos, bem como permite a geração de procedimentos automatizados em poços com baixo nível de informação.

\section{Agradecimentos}

Os autores gostariam de agradecer o apoio do CNPq, ANP e do Cepetro - Centro de Estudos de Petróleo - Unicamp para a realização desse trabalho. 


\section{Referências} bibliográficas

AVSETH, P., MUKERJI, T., JORSTAD, A., MAVKO, G., VEGGELAND, T. Seismic reservoir mapping from 3-D AVO in a North Sea turbidite system. Geophysics v. 66, n.4, p. 1157-1176, 2001.

BACKER, E. Computer-assisted reasoning in cluster analysis. Prentice Hall International Ltd., Hemel Hempstead, U.K.,1995. 367p.

BHATT, A., HELLE, H. Determination of facies from well logs using modular neural networks. Pet. Geosci., v. 8, n.3, p. 217 228, 2002.

BUCHEB J.A. Aplicação de tratamento estatístico multivariante em dados de perfis de poços da bacia de Sergipe, Alagoas. Belém: CG/UFPA, 1991. 136p. (Tese de Mestrado).

BUSCH, J. M., FORTNEY, W. G., BERRY L. N. Determination of lithology from well logs by statistical analysis, $\mathbf{S P E}$ Formation Evaluation, v. 2, p.412-418, 1987

COUTO N.A.P. Construção de banco de dados petrofísicos para determinação automática de litologias. Belém: CG/ UFPA, 1994. (Tese de Mestrado em Geofísica).

CUDDY, S. Litho-facies and permeability prediction from electrical logs using fuzzy logic. SPE Reserv. Evalu. Eng., v. 3, n. 4, p.319-324, 2000.

DAVIS, J.C. Statistics and data analysis in geology. (Third Edition). John Wiley \& Sons, 2002. p. 11-487
DOVETON J.H. Geologic log analysis using computer methods. Am. Assoc. Petroleum Geologists, Computer Methods in Geology, n. 2, 169p., 1994.

FISCHER, R.A. The statistical utilization of multiple measurements, Annals of Eugenics, v. 7, p.179-188, 1936.

FLEXA, R. T., ANDRADE, A., CARRASQUILLA, A. Identificação de litotipos nos perfis de poço do Campo de Namorado (bacia de Campos, Brasil) e do lago Maracaibo (Venezuela) aplicando estatística multivariada. Revista Brasileira de Geociências, v. 34, n. 4, p.571578, 2004.

GORDON, A. D. Classification. Chapman \& Hall/CRC, Boca Raton, Fla., p.256, 1999.

JOHNSON, R.A., WICHERN, D.W. Applied multivariate statistical analysis, (3rd ed.). Prentice-Hall, 1992. 642p.

KAUFMAN, L., ROUSSEEUW, P.J. Finding groups in data, an introduction to cluster analysis. New York: John Wiley \& Sons, Inc., 1990. p.342.

LI, Y., ANDERSON-SPRECHER, R. Facies indentification from well logs: a comparasion of discriminant analysis and Naïve Bayes classifier. Journal of Petroleum Science and Engineering, v.56, p. 149-157., 2006

RIDER, M. The geological interpretation of well logs. (Second Edition) Sutherland, Scotland: Rider-French Consulting Ltd, 2000. 280 p.

ROSA, H. Estudo da caracterização de eletrofácies por meio de perfís de poços e de amostras de testemunhos utilizando estatística multivariada. 2006. 280p. (Tese de Doutorado em Ciências e Engenharia de Petróleo).

SCHLUMBERGER. Log interpretation - principles/applications. N.Y.: Schlumberger Ltd., 1987. 198 p.

SERRA, O. Fundamentals of well-log interpretation - 2. The interpretation of logging data, developments in petroleum science (15B), Elsevier Science Publishers B.V., 1986a. 684p.

SERRA, O. Sedimentary environments from wireline logs. N.Y.: Schlumberger, 1986b. 211p.

SUSLICK, S.B., SCHIOZER, D. J. Risk analysis applied to petroleum exploration and production: an overview. Journal of Petroleum Science and Engineering, v. 44, n.2, p.1-9, 2004.

TABACHNICK, B. G., FIDELL, L. S.Using multivariate statistics. New York: HarperCollins College Publisher, 1996. 996 p.

TANG, H., WHITE, C., ZENG, X., GANI, M., BHATTACHARYA, J. Comparison of multivariate statistical algorithms for wireline log facies classification. AAPG Annual Meeting Abstract, v. 88, p. 13, 2004.

Artigo recebido em 15/08/2007 e aprovado em 12/06/2008.

\section{A REM tem novo endereço: Rua Carlos Walter Marinho Campos, 57 Bairro: Vila Itacolomy 35400-000 - Ouro Preto - MG}

$* * * * * * * * * * * * * *$

www.rem.com.br 